\title{
The Effect of Counseling on Self-Esteem and Health-promoting Behaviors in Psychiatric Patients Receiving Electroconvulsive Therapy: A Clinical Trial Study
}

\author{
Parisa Rostami $^{1}$, Efat Sadeghian ${ }^{2 *}$, Ali Akbari $^{3}$
}

1. Psychiatric Nurse, Hamadan University of Medical Sciences, Hamadan, Iran

2. Associated Professor, Chronic Diseases (Home Care) Research Center, Hamadan University of Medical Sciences, Hamadan, Iran

3. Student, Student Research Center, School of Nursing and Midwifery, Hamadan University of Medical Sciences, Hamadan, Iran

\section{Article Info}

Received: 2021/01/20;

Accepted: 2021/10/22;

Published Online: 2021/12/21

10.30699/ajnmc.29.4.328

Original Article

Use your device to scan and read the article online

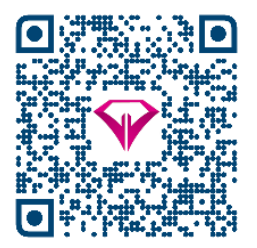

\section{ABSTRACT}

Introduction: Compared to the general population, patients with psychiatric disorders, especially patients receiving electroconvulsive therapy due to its nature, and lack of psychiatric nursing counseling have worse physical health and lower self-esteem. The aim of this study was to determine the effect of psychiatric nursing counseling on self-esteem and health-promoting behaviors of patients receiving electroconvulsive therapy in hospitalized patients.

Methods: This clinical trial was conducted on 114 patients undergoing ECT at Farshchian Hospital in Hamadan, Iran, in 2019. The participants were divided into two groups of intervention $(\mathrm{n}=57)$ and control $(\mathrm{n}=57)$ by block randomization. Data collection tools included demographic, Rosenberg self-esteem, and health-promoting behaviors questionnaires. The intervention in the experimental group was held in the form of 4 sessions of individual counseling. Data were analyzed using frequency, percentage, mean and standard deviation statistics, Chi-square and ttests in SPSS software version 20.

Results: The mean (standard deviation) of self-esteem score before the intervention in the experimental group 21.60 (4.01) and control 21.95 (3.51) was not significantly different $(P=0.542)$. But the mean score of self-esteem immediately after the intervention in the experimental group 25.47 (3.91) and in the control group was 19.11 (2.79) and two weeks after the intervention, which was significant $(P<0.001)$. The mean and standard deviation of the healthpromoting behaviors before intervention in the control group 96.67 (6.028) and intervention group 92.44 (5.444) were statistically significant $(P<0.05)$. Also, this difference was significant between the intervention group 91.30 (51.539) and the control group 83.12 (5.976) immediately and two weeks after the intervention $(P<0.001)$.

Conclusion: Psychiatric counseling increased self-esteem and prevented a decline in healthpromoting behaviors. Therefore, this method can be used in educational programs and nursing care for patients with mental disorders.

Keywords: Counseling, Psychiatric nursing, Self-esteem, Health promotion, Mental disorders, Electroconvulsive therapy

\section{How to Cite This Article:}

Rostami P, Sadeghian E, Akbari A. The Effect of Counseling on Self-Esteem and Health-promoting Behaviors in Psychiatric Patients Receiving Electroconvulsive Therapy: A Clinical Trial Study. Avicenna J Nurs Midwifery Care. 2021; 29 (4) :328-339 
تأثير مشاورهروان يرستارى برعزتنفس و رفتارهاى ار تقاءدهندهُ سلامت بيماران مبتلا به اختلالات روانى دريافت كنندهُ الكتروشوك درمانى: يكى مطالعة كار آزمايى بالينى

يريسا رستمى'، عفت صادقيان ‘ على اكبرى

I. كارشناسى ارشد روان برستارى، دانشكاه علوم يزشكى همدان، همدان، ايران

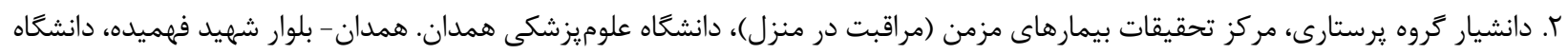

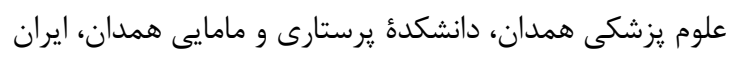

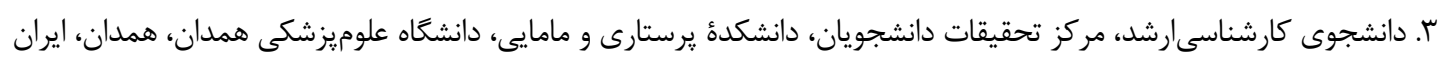

\begin{tabular}{|c|c|}
\hline جكيده & اطلاعات مقاله \\
\hline 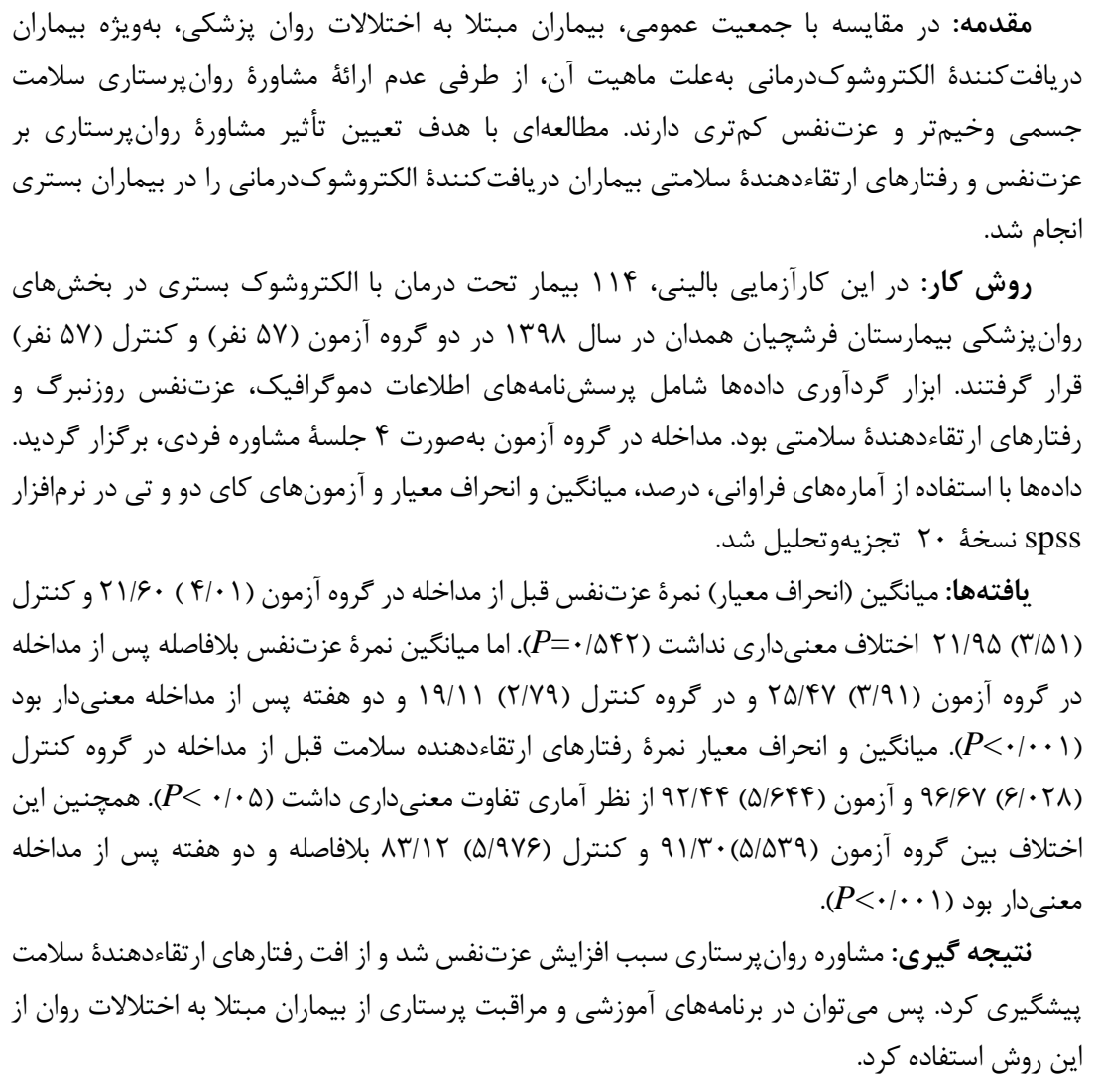 & 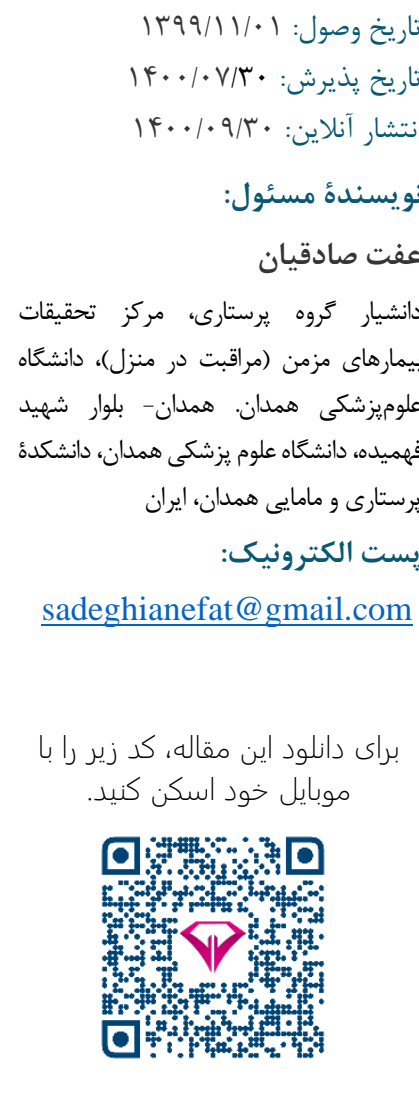 \\
\hline & \\
\hline
\end{tabular}

مقدمه

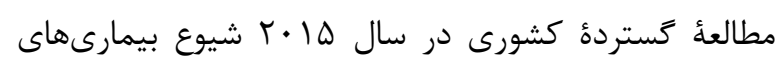

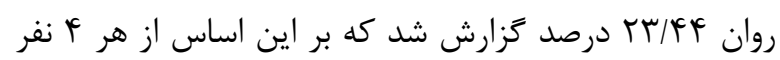

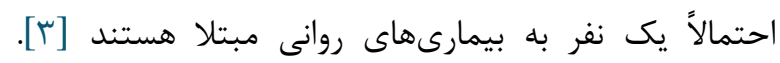

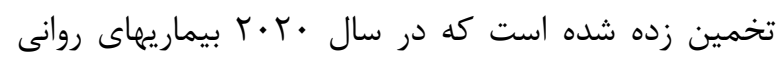

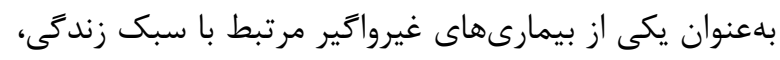

بيمارىهاى روانى در رديف تأثير كذارترين اختلالات

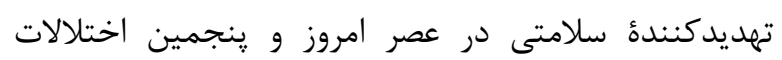

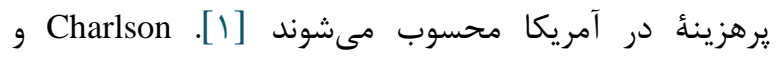

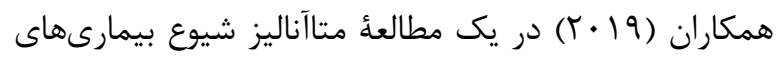

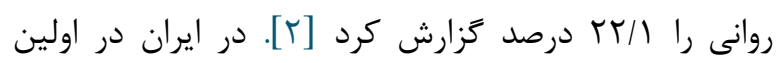


بيشتر بيماران دريافت كنندة الكتروشوك درمانى، منبع اصلى دريافت اطلاعات لازم در مورد اين روش درماني دئى را ساير

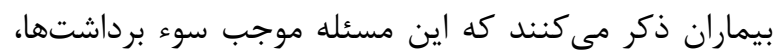

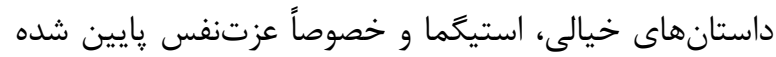

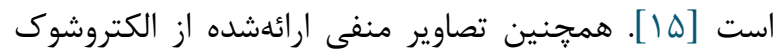

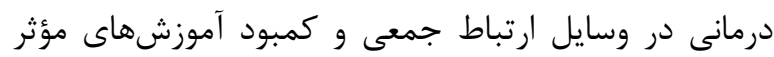

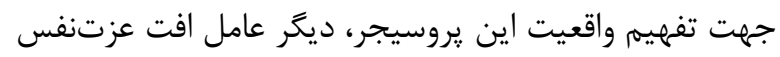

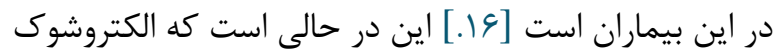
درمانى بهعلت تأثير فراوان، بهعنوان يكى روش مفيد و مؤثر إنر

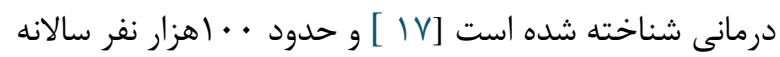

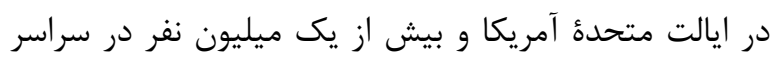

جهان سالانه الكتروشوك دريافت مى كنند [1 ll]. روان يرستاران بر اساس ماهيت شغلى خود به نسبت ساير

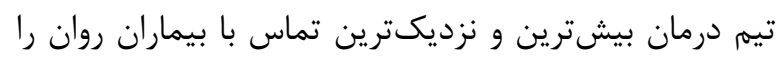

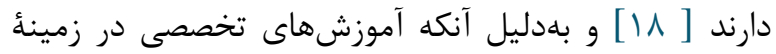
سلامت روان دريافت كردهاند، مىتوانند بهصورت مستقل به اله

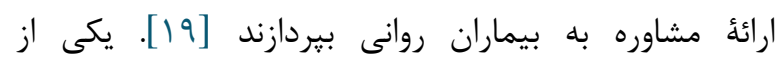
استراتزىهاى مؤثر براى كمك به بيماران مبتلا به اختلالات

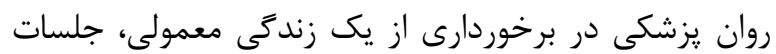

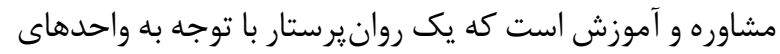

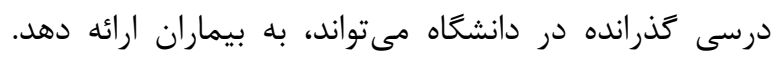
مشاوره يكى از مهمترين و تخصصىترين خدمات راهنمايى دراني

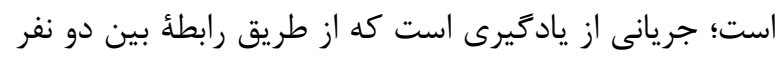

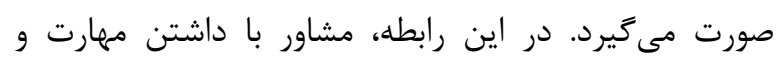

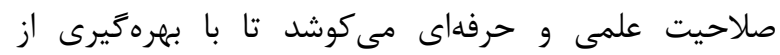
روشهاى منطبق بر نيازمندىهاى مراجع او را يارى كند تا

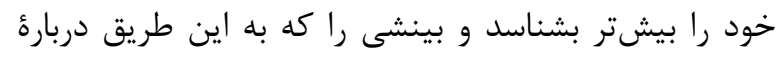

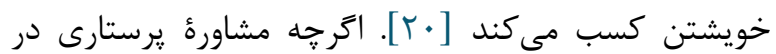
سرويسهاى متفاوت يزشكى، مانند سرويس قلب و عروق و

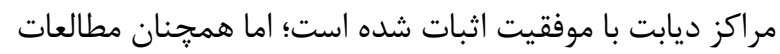

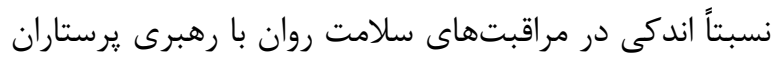

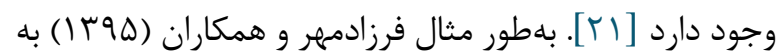
بررسى تاثير مشاورة يرستارى بر اضطراب و رضايتمندى

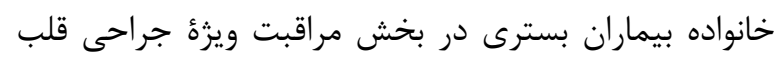
يرداختند و نتايج مطالعه دلالت بر كاهش اضطراب و افزايش رضايتمندى گروه هدف مطالعه داشت [r [T]. در بيمار ان مبتلا به اختلالات روان يزشكى، بلويزه بيماران دريافت كنندة الكتروشوك درمانى بهعلت ماهيت آن، از طرفى بلى عدم ارائه
علت Vورد از •ا مورد مرى در كشورهاى درحالتوسعه

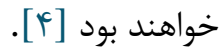
در مقايسه با جمعيت عمومى، بيماران روانى بهخصوص

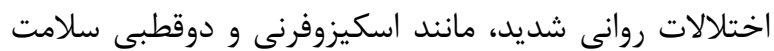
جسمى وخيمتر و اميد به زندكى كمترى دارند. در اين بيماران

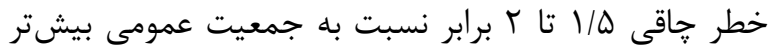

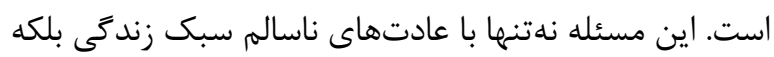
با عوارض داروهاى آنتىسايكوتيك نيز در ارتباط است [ه].

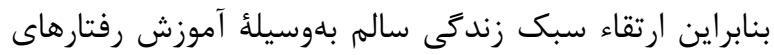

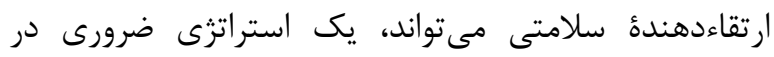

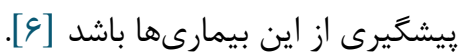
رفتارهاى ارتقاءدهندة سلامتى شامل كلئ فعاليتهاى مشوق در زمينه جسمى، روحى و عملكرد روانى بدون توجه به سلامت و يا بيمار بودن فرد است. بيشتر اين فعاليتها بهوطور

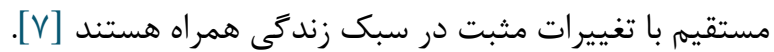
فعاليتهاى ارتقاءدهندهُ سلامتى در جستجوى تقويت ميزبان جهت افزايش دانش بهداشتى، تغييرات محيط، مداخلات

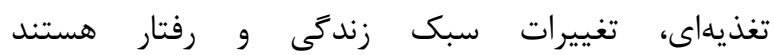

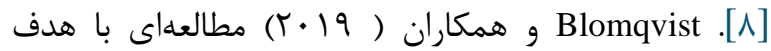

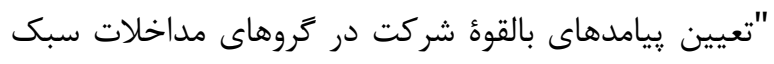
زندگى در اشخاص با اختلالات سايكوتيك" در كشور سوئد

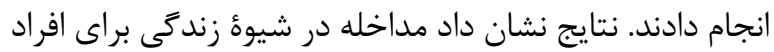
داراى بيمارى روانى شديد مىتواند براى افزايش فعاليت بدنى ندانى

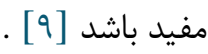

يكى از فاكتورهاى مؤثر در ارتقاء سلامت جسمى و إنى روحى افراد عزتنفس است. عزتنفس بلهعنوان انعكاسى از خود

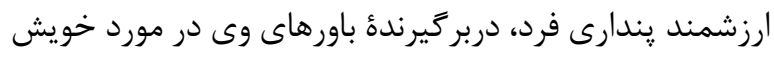

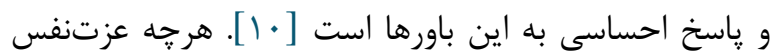

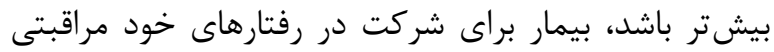

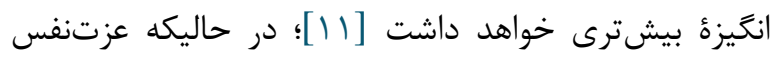

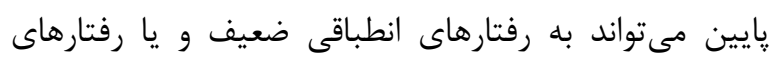

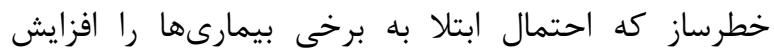
ميدهند، منجر شود [1/]]. طبق مطالعة Yoo و و همكاران

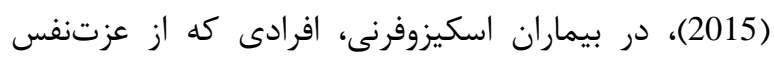
كمترى رنج مىبرند، با احتمال بيشترى در خطر افكرار افرى

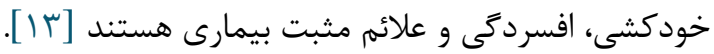

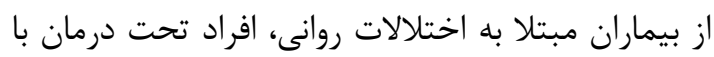
الكتروشوى درمانى از عزتنفس كمترى رنج مىبرند [1F]

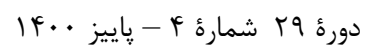


نرمافزار R حاصل شد (A= آزمون و B= كنترل). يس از مشخص شدن توالى تصادفى هر يك از اين توالىها روى يك إنى كارت ثبت و در داخل ياكتهاى در بسته (sealed envelope)

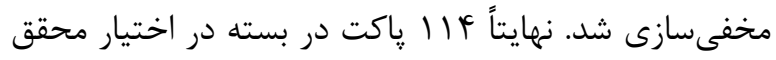
اصلى قرار كرفت (شكل (1).

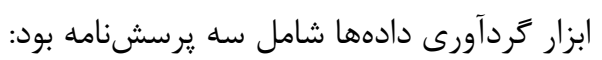

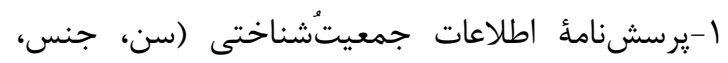

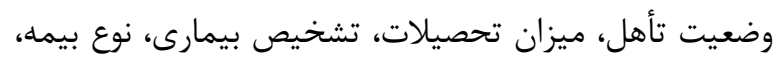

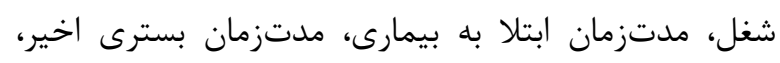

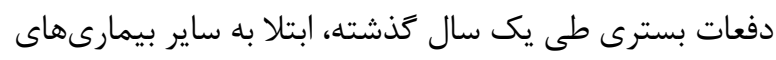

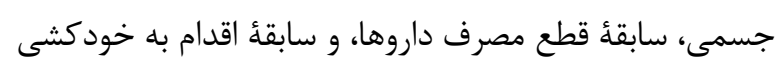

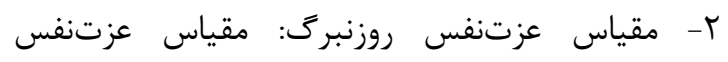
روزنبرى در سال 1980 توسط روزنبرى ساخته شده است.

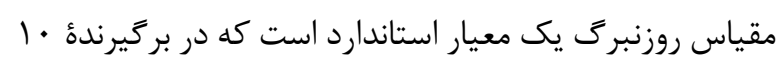

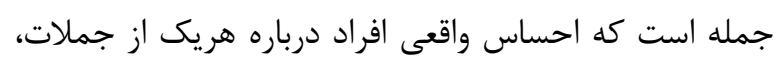

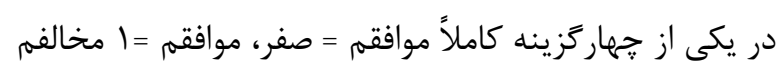

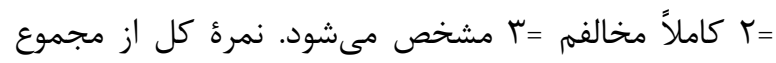

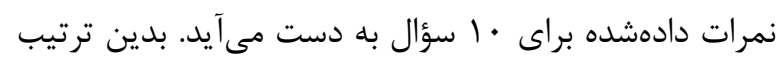

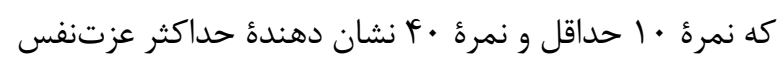

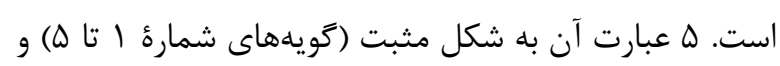
ه عبارت ديخر بهصورت منفى (كويههاى شمارة 9 تا • ل () ارائه

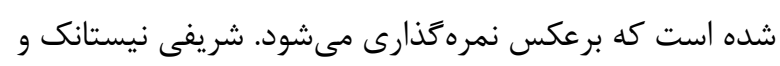

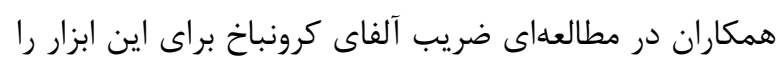

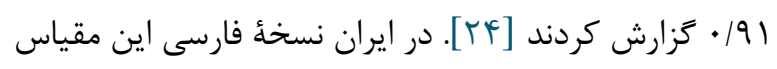

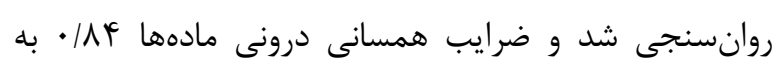

دست آمد [TST].

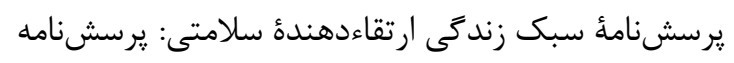

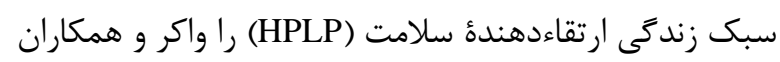

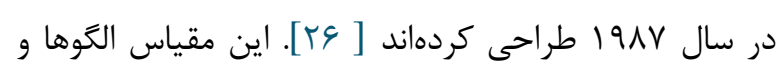

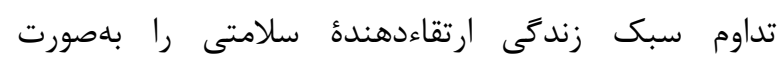

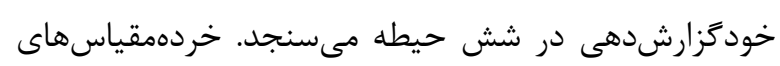

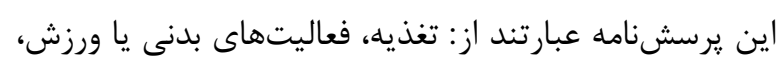

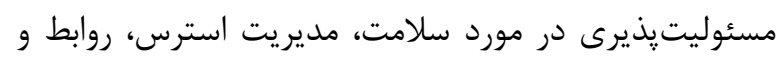

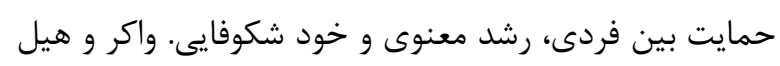

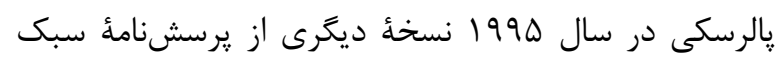

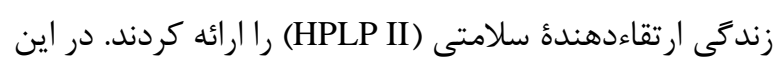

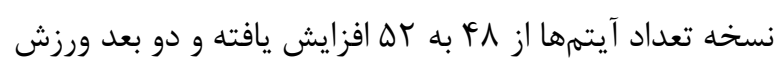

مشاورة روانيرستارى بلعلت به كاركيرى نامناسب روان

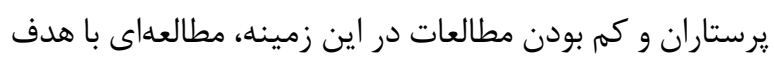

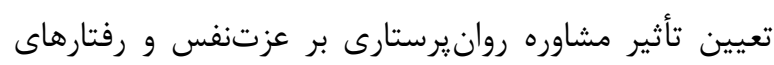

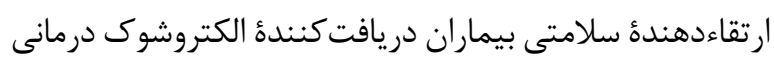
در بيمار ان بسترى طراحى شده است تا با استفاده از نتايج آن آن

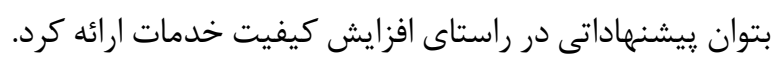

$$
\text { روش كار }
$$

يزوهش حاضر يك مطالعة كار آزمايى بالينى، با طرح قبل

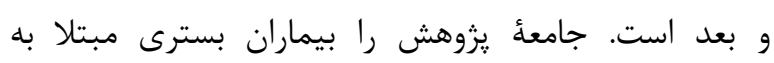

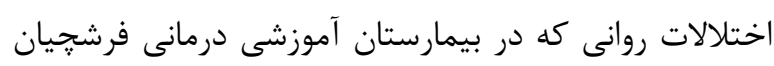

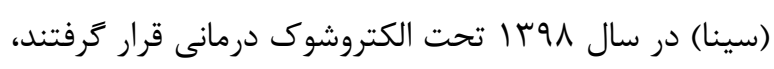
بودند. حجم نمونه براساس مطالعة مشابه [بآ]، سطح اطمينان آزمون (

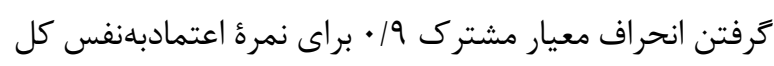

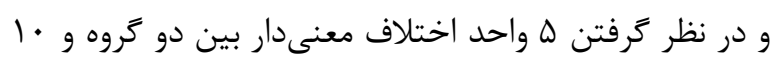

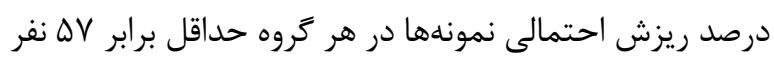

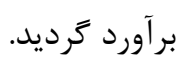

$$
n=\frac{\left(z_{1-\frac{\alpha}{2}}+z_{1-\beta}\right)^{2}\left(\sigma_{1}^{2}+\sigma_{2}^{2}\right)}{\left(\mu_{1}-\mu_{2}\right)^{2}}
$$

معيارهاى ورود به مطالعه، شامل تشخيص اختلال

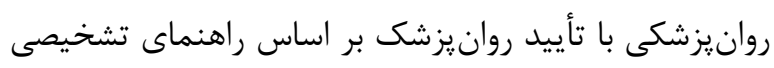

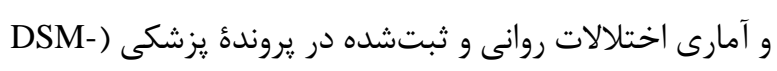

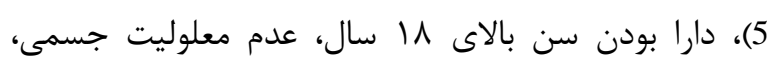

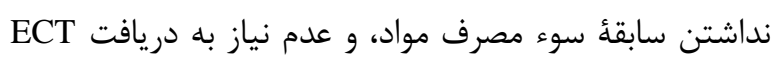

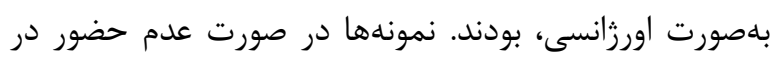

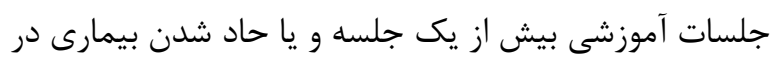

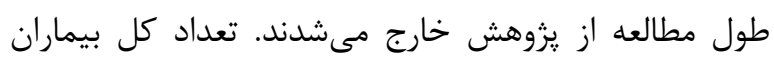
بسترى در بخشهاى روان يزشكى بيمارستان فرشجيان سينا

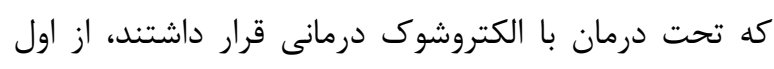

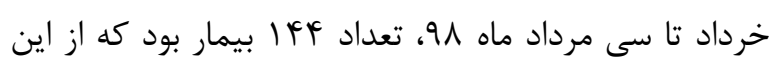

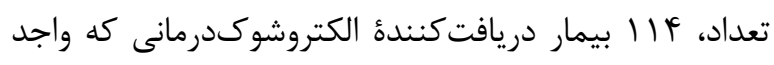

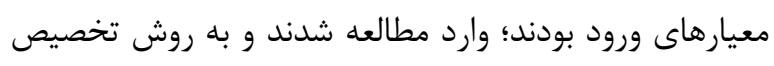

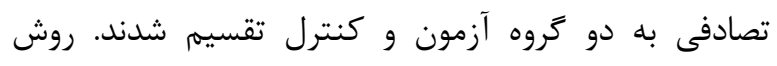

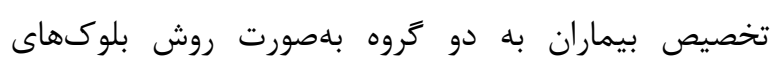

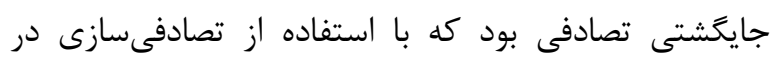

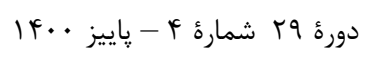


در كروه آزمون بهصورت برَزارى جلسات مشاورة

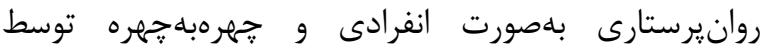

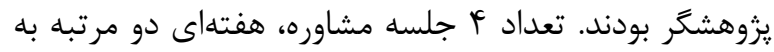

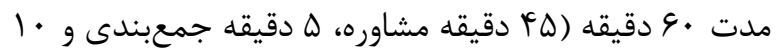
دقيقه يرسش و ياسخ) در يكى از اتاقهاى مشاوره و ويزيت

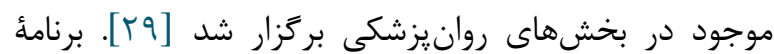

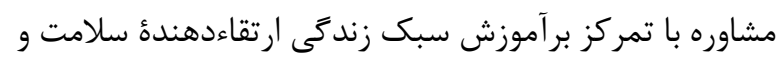

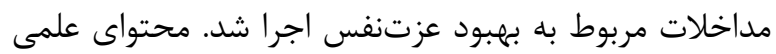

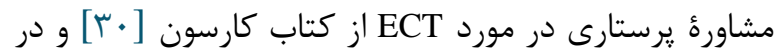

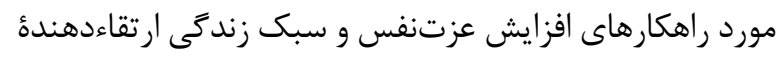

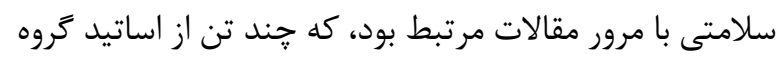
روانيرستارى آن را مطالعه و تأييد كردند (عناوين مداخلات در ادامه، در جدول الرائه شده است). يرسشنامهامهاى

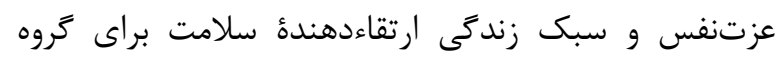

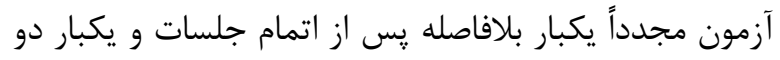
هفته يس از كذشت آخرين جلسه تكميل شدند. در كروه

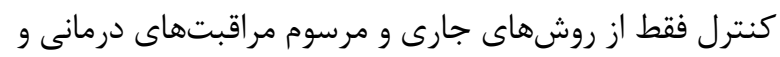

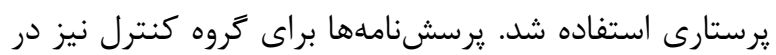

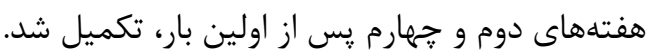

و خودشكوفايى به فعاليت بدنى و رشد معنوى تغييرعنوان

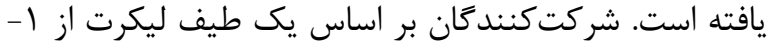

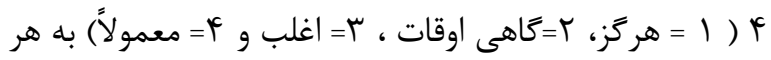

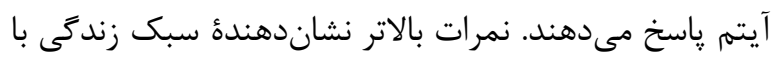

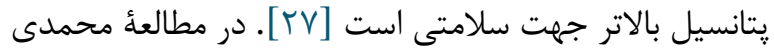

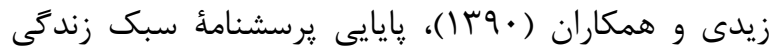

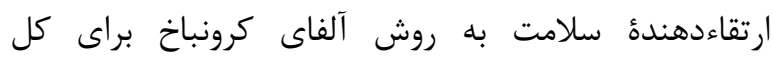
يرسشنامه برابر با AYT/ • به دست آمده است و آلفاى كرونباخ زيرشاخههاى تغذيه، فعاليت جسمى، مسئوليت يذيرى در مورد

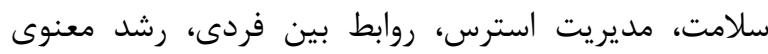

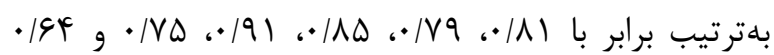

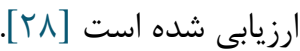

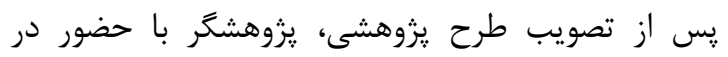

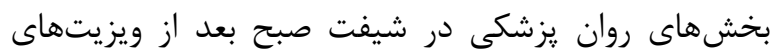

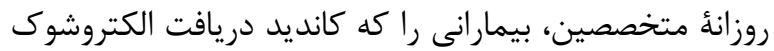

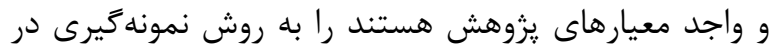

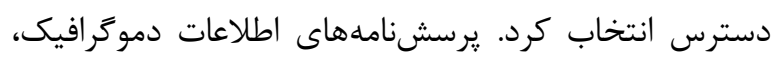
عزتنفس و سبك زندگى ارتقاءدهنده سلامتى در ساعاتى كه

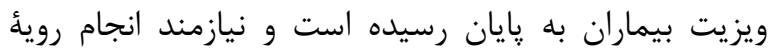
خاصى نبودند؛ با حضور و نظارت يزوهشك بكر تكميل شد. مداخله

جدول ا: الكَوى جلسات مشاوره در كَروه مداخله در قالب جدول زير بيان شده است:

ملاحظات اخلاقى از جمله، اخذ مجوز از كميتهٔ اخلاق با كد اخلاقى IR.UMSHA.REC.13960.265، تكميل فرم رضايت
اين مطالعه در مركز كارآزمايى بالينى ايران به شماره IRCT2017061933378N3

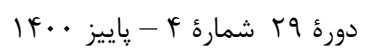


يريسا رستمى و همكاران بrr

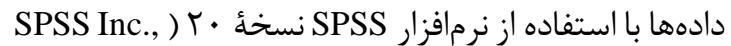

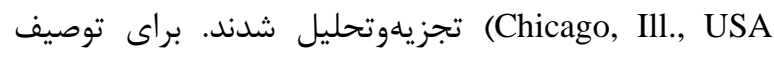

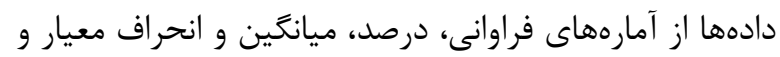

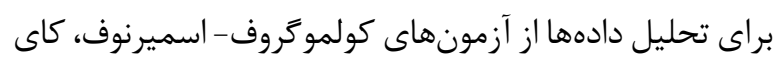
دو، تى زوجى و تى مستقل استفاده شده است.
آكاهانهُ كتبى توسط شركت كنندَان در يزوهش، اطمينان

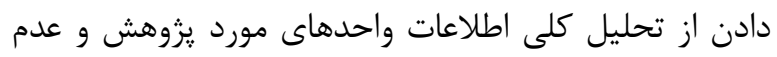

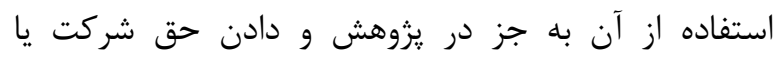

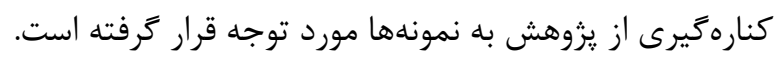

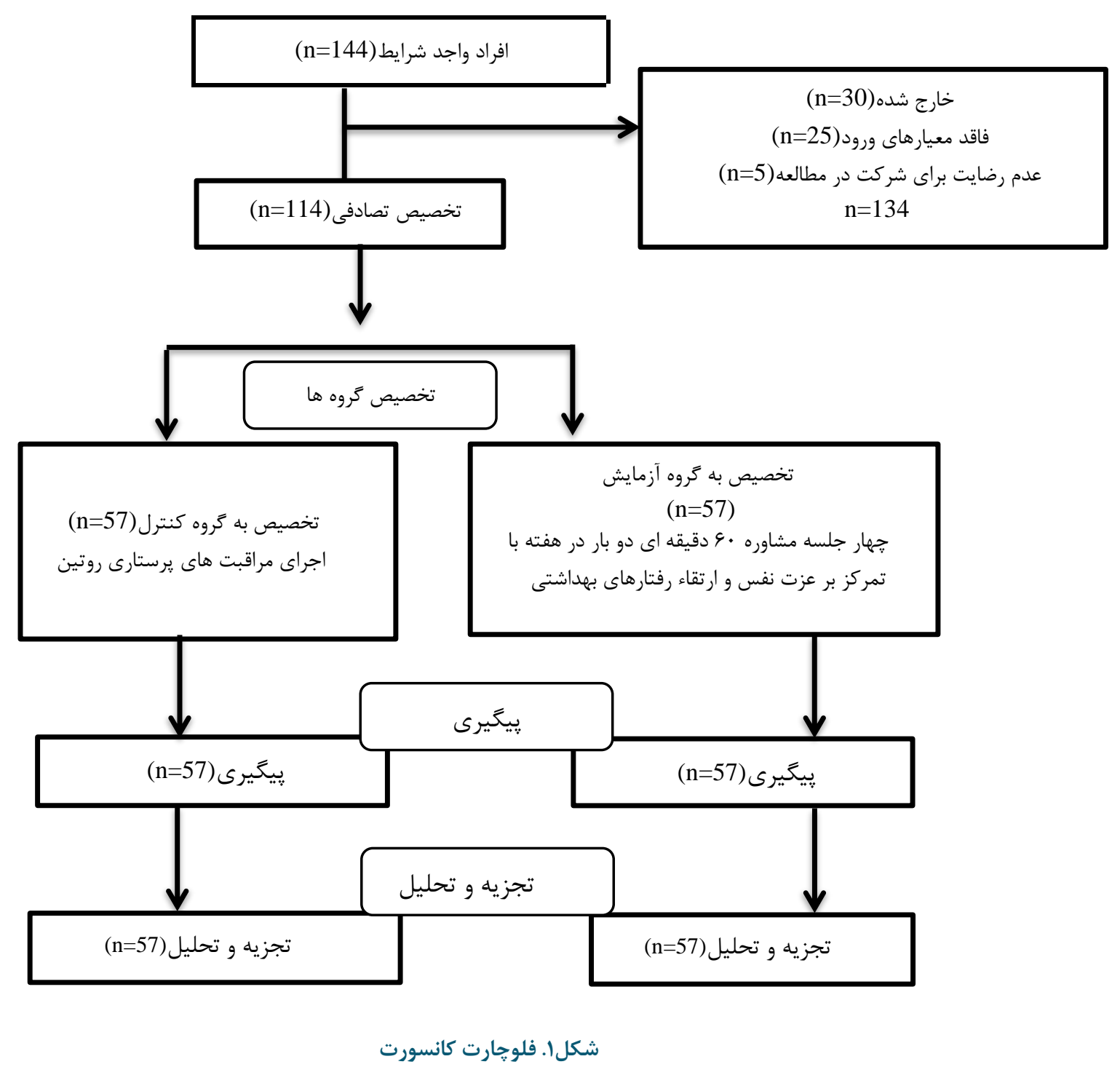

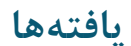

از لحاظ متغيرهاى فوق همسان بودند. اكثريت بيماران مورد

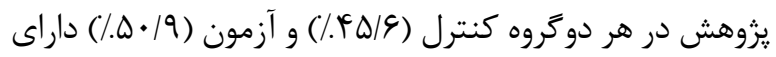

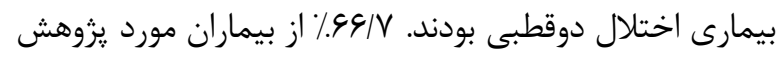

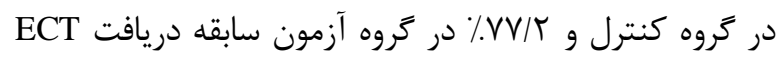

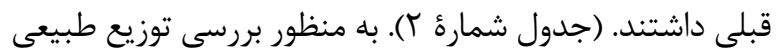

نتايج نشان داد، بيشتر بيماران مورد يزوهش در گروه

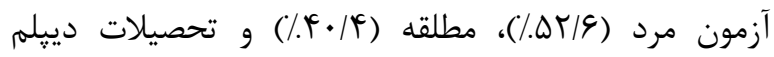

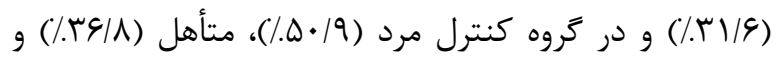

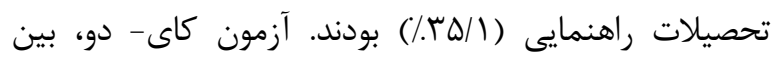

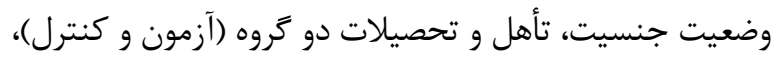
اختلاف معنى دارى از نظر آمارى نشان نداد. لذا بيماران دو تروهي دروه 
قبل از مداخله در كروه آزمون ميانكين نمره رفتارهاى

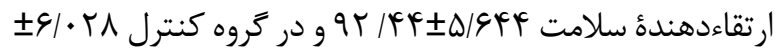
9\&/9V بود. آزمون آمارى تى نشان داد، بين ميانكَين نمرات

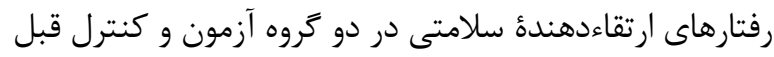

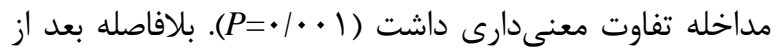

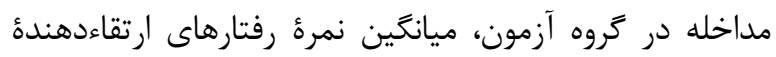

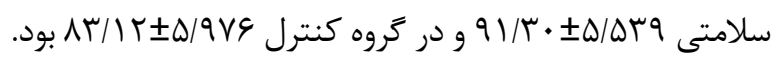
نتايج آزمون تى نشان داد كه بين ميانخين نمرةٔ رفتارهاى

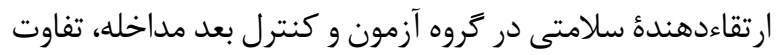

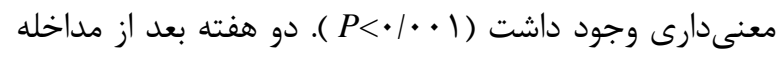

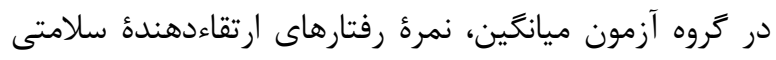
آ

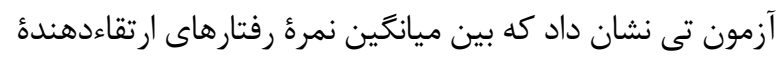

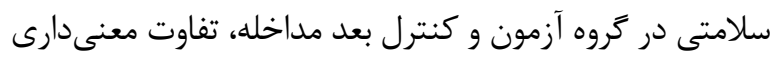

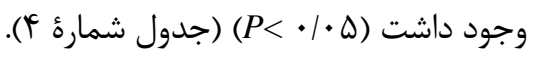

دادهها از آزمون كولموكروف- اسميرنوف استفاده شد .$(P<\cdot / \cdot \omega)$

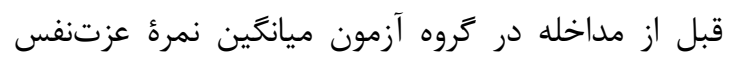

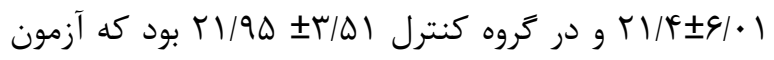

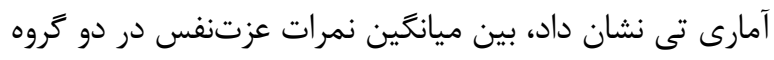

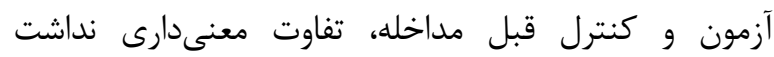
(P=•/VMA)

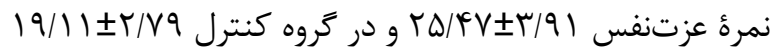
بود. كه نتايج آزمون تى نشان داد كآ كه بين ميانگين نمرة

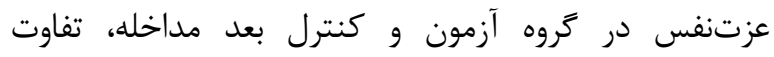

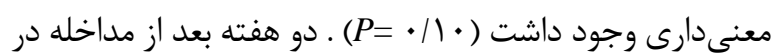

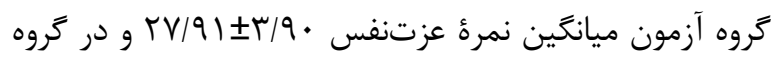

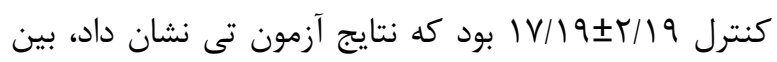

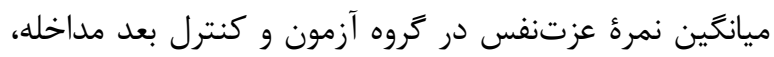
تفاوت معنى دارى وجود داشت (1 • • • >P) (جدولشمارة ب).

جدول ז: مشخصات دموكر افيك واحدهاى يثوهش در كروه كنترل و آزمون

\begin{tabular}{|c|c|c|c|c|c|}
\hline \multirow{2}{*}{ P-value } & \multirow{2}{*}{ Test } & مداخله(AV) & كنترل(AV) & \multirow{2}{*}{ متغير } & \\
\hline & & تعداد(درصد) & تعداد (درصد) & & \\
\hline$\cdot / 4 \cdot 9$ & $\mathrm{t}=\cdot / \Lambda \uparrow \Lambda$ & $|\varphi| /|q \pm| r / q V$ & $R r / T \Delta \pm I r / q r$ & سن & \\
\hline \multirow{2}{*}{$\cdot|\wedge \Delta|$} & \multirow{2}{*}{$\chi^{2}=\cdot 1 \cdot r \Delta$} & $r \cdot(\Delta r / \varphi)$ & rq $(0 \cdot / 9)$ & مرد & \multirow{2}{*}{ جنس } \\
\hline & & $r V(F V / F)$ & $r \wedge(r q / l)$ & 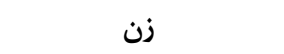 & \\
\hline \multirow{4}{*}{-/^৭४ } & \multirow{4}{*}{$\chi^{r}=\cdot \mid q \cdot r$} & $\Delta(N \wedge)$ & $f(V)$ & مجرد & \multirow{4}{*}{ وضعيت تاهل } \\
\hline & & $19(r / \mu)$ & 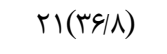 & متاهل & \\
\hline & & $r r(F \cdot / \mathcal{F})$ & $r \cdot(r \Delta / 1)$ & مطلقه & \\
\hline & & $1 \cdot(I V / \Delta)$ & $\mid r(r \mid / 1)$ & بيوه & \\
\hline \multirow{5}{*}{.$/ 499$} & \multirow{5}{*}{$\chi^{2}=r / \Delta \Lambda 1$} & $\Delta(N \vee)$ & $f(9 / 9)$ & بيسواد & \multirow{5}{*}{ تحصيلات } \\
\hline & & $11(19 / \pi)$ & $19(Y N \mid)$ & ابتدايى & \\
\hline & & $19(Y N \mid)$ & $r \cdot(r \Delta / 1)$ & راهنمايى & \\
\hline & & $\mid \wedge(r \mid / \varphi)$ & $\mid F(Y F / \varepsilon)$ & دييلم & \\
\hline & & $V(I T / T)$ & $r(\Delta / r)$ & ليسانس & \\
\hline \multirow{5}{*}{ - /Arq } & \multirow{5}{*}{$\chi^{2}=r / \cdots r$} & $\mid F(Y Y / \varepsilon)$ & $\mid r(Y \mid)$ & خانهدار & \multirow{5}{*}{ 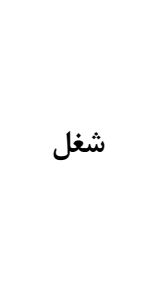 } \\
\hline & & $9(1 \cdot 10)$ & $\Delta(N \wedge)$ & كارمند & \\
\hline & & $19(r / \mu)$ & $19(Y N \mid)$ & بيكار & \\
\hline & & $9(10 / \Lambda)$ & $10(r g / r)$ & بازنشسته & \\
\hline & & $9(1 \Delta / \Lambda)$ & $9(1 \Delta / \Lambda)$ & آزاد & \\
\hline \multirow{2}{*}{ (9T/. } & \multirow{2}{*}{$\chi^{2}=\cdot / 4 \lambda$} & $\mid F(Y F / G)$ & $\mid F(Y F / \varphi)$ & اختلال افسردَى اساسى & \multirow{2}{*}{ نوع بيمارى } \\
\hline & & $r q(0 \cdot / 9)$ & $r \xi(F \Delta / G)$ & اختلال دوقطبى & \\
\hline
\end{tabular}


يريسا رستمى و همكاران هبr

\begin{tabular}{|c|c|c|c|c|c|}
\hline \multirow{2}{*}{ P-value } & \multirow{2}{*}{ Test } & مداخله (هV) & كنترل(AV) & \multirow{2}{*}{\multicolumn{2}{|c|}{ متغير }} \\
\hline & & تعداددرصد) & تعداد (درصد) & & \\
\hline \multirow{4}{*}{.1 .49} & \multirow{4}{*}{$\chi^{2}=r / M 1$} & $V(\mid r / r)$ & $9(1 \Delta / \Lambda)$ & اسكيزوفرنى & \\
\hline & & $V(\mid Y / r)$ & $\wedge(1 f)$ & ساير بيمارىها & \\
\hline & & $r r(\Delta V / q)$ & $F_{\Delta}\left(\varepsilon 1 / f^{4}\right)$ & ندارد & ساير بيمارىهاى \\
\hline & & $T F(F T /))$ & Tr(TNG) & دارد & جسمى \\
\hline \multirow{2}{*}{$\cdot|r| 1$} & \multirow{2}{*}{$\chi^{2}=1 / \Delta A Y$} & $19(r T / Y)$ & $I T(Y r / \Lambda)$ & خير & سابقه دريافت ECT \\
\hline & & $r_{\Lambda}(99 / V)$ & $\mu \kappa(V V / r)$ & بلى بلى & قبلى \\
\hline \multirow{2}{*}{$\cdot / v \cdot 9$} & \multirow{2}{*}{$\chi^{2}=\cdot / \| \kappa$} & $r I(\Delta F / F)$ & $r r(\Delta V / q)$ & خير & \multirow{2}{*}{ سابقه خودكشى } \\
\hline & & $r \xi(Y \Delta \mid G)$ & $T F(F Y / I)$ & 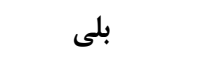 & \\
\hline
\end{tabular}

جدول ": مقايسه ميانكين نمره عزت نفس در كروه كنترل و آزمون

\begin{tabular}{|c|c|c|c|c|}
\hline \multirow{2}{*}{ P-value } & \multirow{2}{*}{$\mathbf{t}$} & ميانكَين(انحراف معيار) & ميانَين(انحراف معيار) & \multirow{2}{*}{ عزت نفس } \\
\hline & & مداخله & كنترل(n=QV) & \\
\hline$\cdot / \vee \wedge \wedge$ & $\cdot \cdot V r$ & $r \mid / F \pm \varepsilon \cdot 1 \cdot 1$ & $r \mid q \Delta \pm \Psi / \Delta)$ & قبل از مداخله \\
\hline $.1 \cdot 10$ & 9||$Q \mid$ & $r \omega / \mathcal{F} V \pm r / q 1$ & $19 / 11 \pm r / V 9$ & بلافاصله بعد از مداخله \\
\hline$<\cdot|\cdots|$ & IT/TVK & $T V / q) \pm r / q$. & $1 V / 19 \pm T / 19$ & دو هفته بعد از مداخله \\
\hline
\end{tabular}

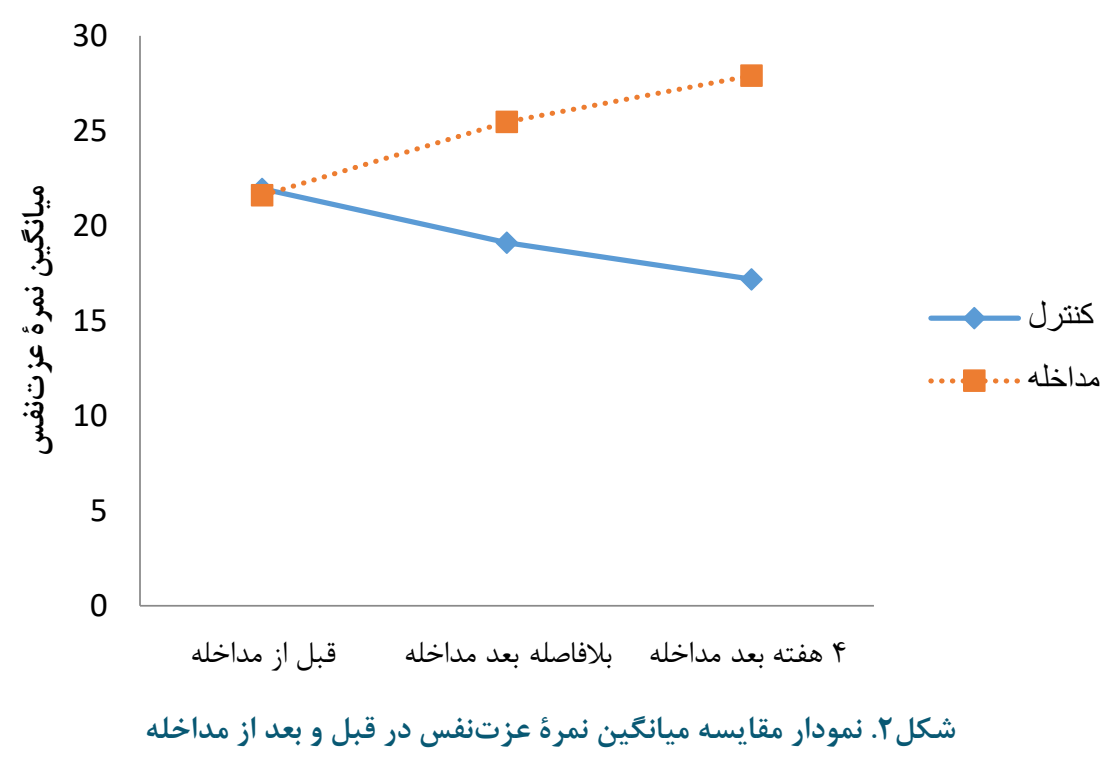

جدول †: مقايسه ميانكَين نمره رفتارهاى ارتقاء دهنده سلامت در تروه كنترل و آزمون

\begin{tabular}{|c|c|c|c|c|}
\hline P-value & $\mathbf{t}$ & ميانكَين(انحراف معيار) & ميانتَين(انحراف معيار) & رفتارهاى ارتقاء دهنده سلامت \\
\hline$<\cdot|\cdot|$ & r/NG9 & 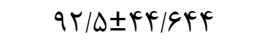 & $Q 9 / 9 \pm 9 V / \cdot Y \Lambda$ & قبل از مداخله \\
\hline$<\cdot / \cdot \cdot 1$ & $-\Delta / \Delta \vee \Delta$ & $q 1 / \Gamma \cdot \pm \Delta / \Delta \Gamma q$ & $\Lambda T / / Y \pm \Delta / q \vee \mathcal{G}$ & بلافاصله بعد از مداخله \\
\hline$<\cdot 1 . \mu r$ & $-t / / V Q$ & $11 / r \checkmark \pm 9 / 9 \% \Delta$ & $V V / \Lambda F \pm V / / r \Lambda$ & دو هفته بعد از مداخله \\
\hline
\end{tabular}




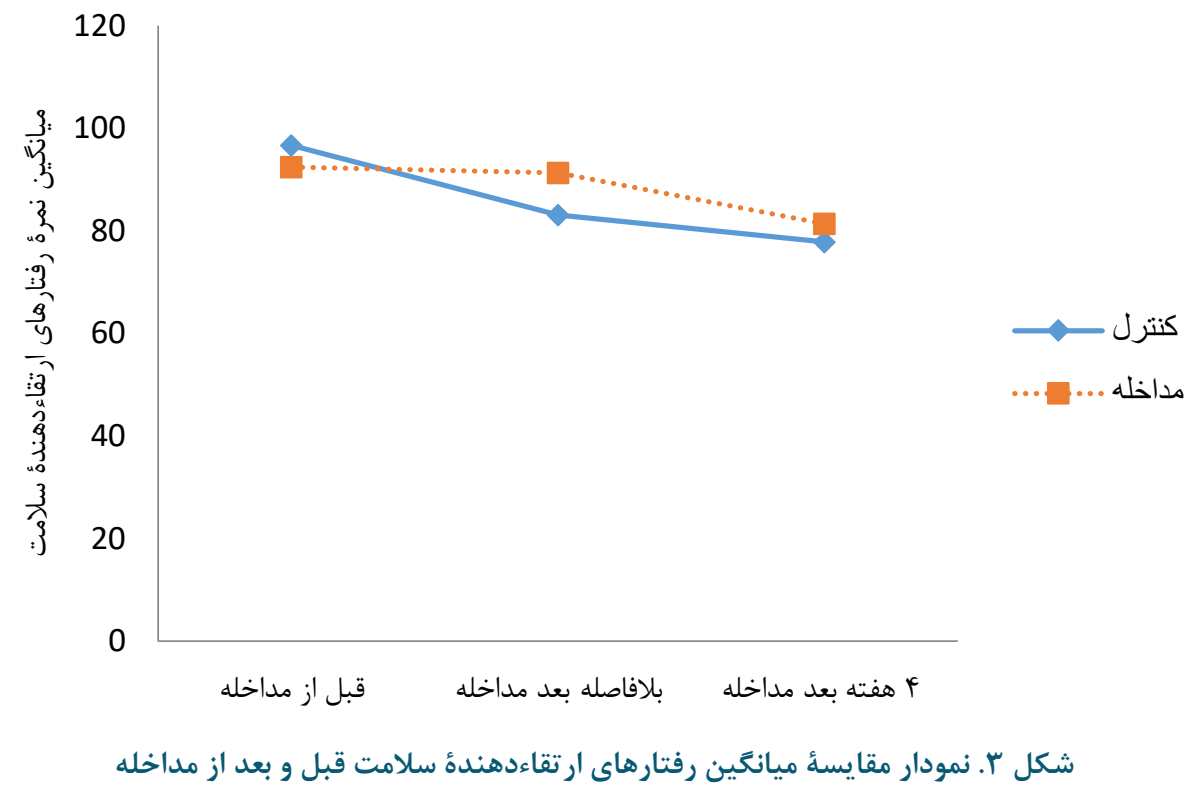

بحث

مشاوره سبب افزايش قدرت كنترل درونى و افزايش توانايىهاى شناختى بيماران روانى مىشود كه بهبود عزتنفس را به دنبال

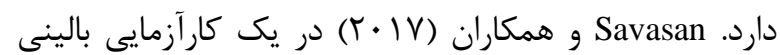
تأثير رويكرد روانيرستارى مبتنى بر الثوى Tidal را بر تطابق و

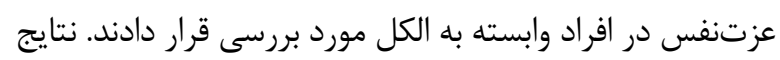
مؤيد افزايش عزتنفس بعد از مداخله بود؛ اما اين افزايش آنقدر

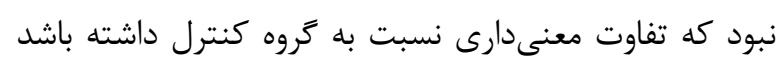

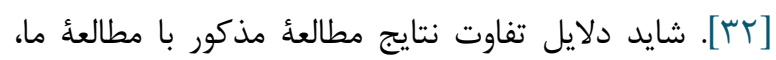
تفاوت در جمعيت مورد مطالعه و الكوى مشاورهاى متفاوت باشد. Mejías گروهى بر علايم افسردگى و اضطراب، عزتنفس و تطابق اجتماعى در دانشجويان مبتلا به اختلال افسردگى و اضطراب انجام دادند. نتايج تفاوت معنى دارى را در كاهش علايم اضطراب

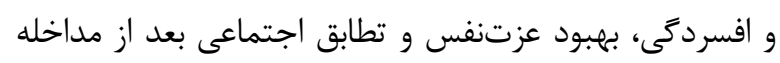

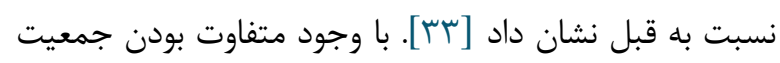
مورد مطالعه و مداخله با مطالعهُ حاضر اما نتايج همسو است.

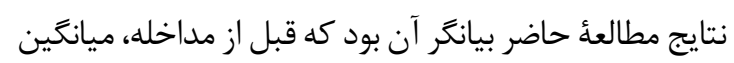
نمره رفتارهاى ارتقاءدهنده سلامتى در گروه كنترل، بيشتر از

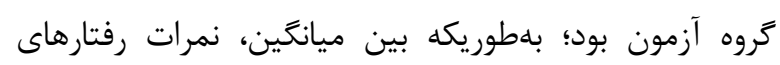

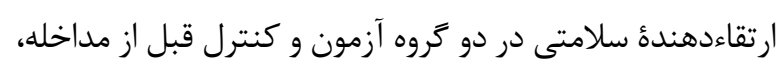
تفاوت معنى دارى وجود داشت. بعد از مداخله، ميانگين نمرة
يزوهش حاضر با هدف تعيين تأثير مشاوره روانيرستارى بر عزتنفس و رفتارهاى ارتقاءدهنده سلامتى بيماران دريافت كننده الكتروشوك درمانى انجام گرفت. نتايج نشان داد بين ميانگين نمرات عزتنفس در دو گروه آزمون و كنترل قبل از مداخله، تفاوت معنى مدارى وجود نداشت. در حاليكه ميانگين نمره عزتنفس بلافاصله بعد از مداخله در مقايسه با قبل از

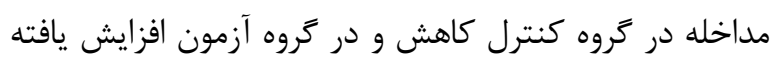
است. بلهوريكه بين ميانخين نمرات عزتنفس در دو گروه آزمون و كنترل بلافاصله بعد از مداخله تفاوت معنى دارى وجود بهدين داشت. همجنين ميانگين نمرهُ عزتنفس دو هفته بعد از مداخله

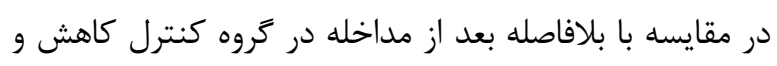

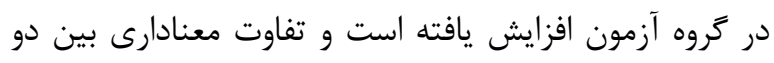
كروه كنترل و آزمون ديده شد. اين بدان معناست كه با ارائه

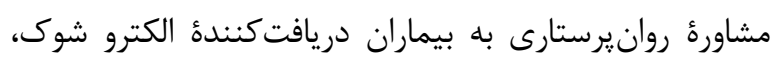
ميزان عزتنفس در آنها افزايش ييدا مى كند. Kim و و همكاران

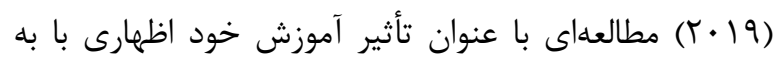

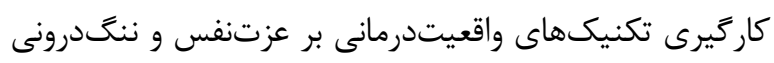

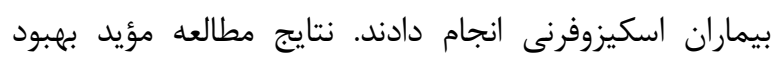
عزتنفس گروه مداخله در مقايسه با گروه كنترل بود [1/ب].

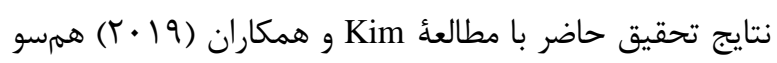
است. شايد دلايل اين همخوانى بتوان جنين تفسير نمود كه 
روانى جدى بعد از كا ماه شركت در مد مداخله ارزيابى شد. نتايج

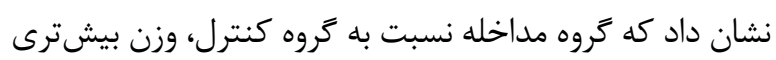

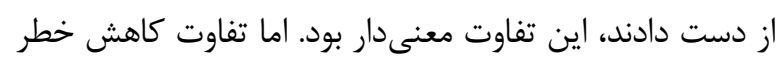

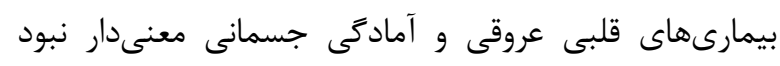

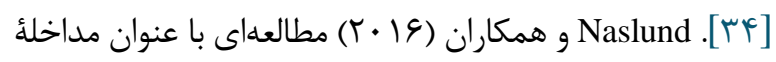

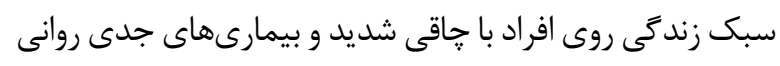

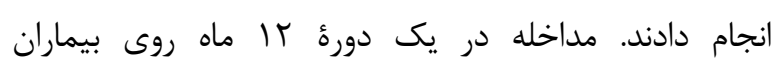

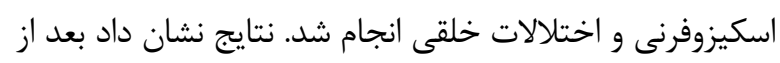

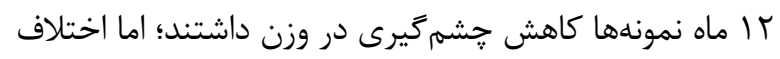

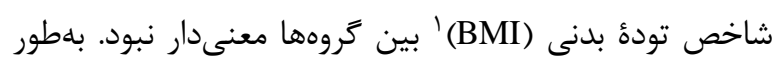

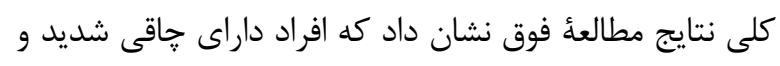

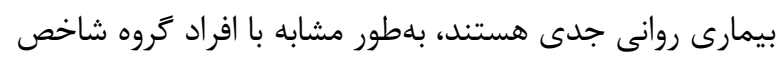

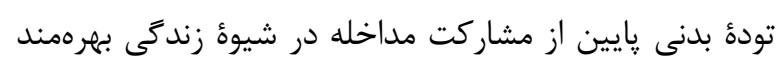

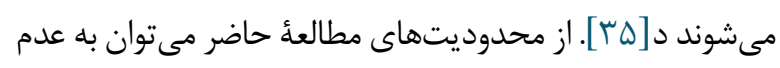

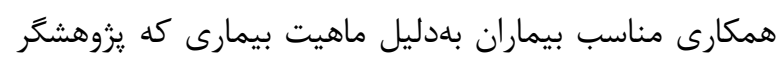

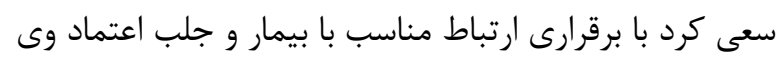

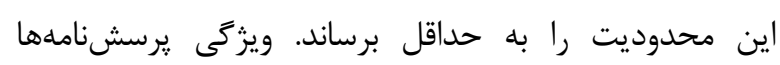

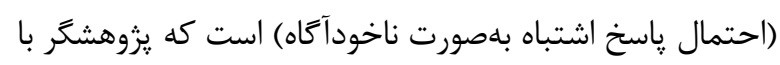

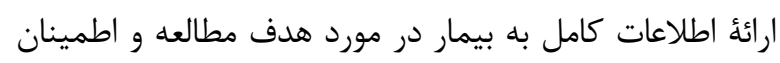

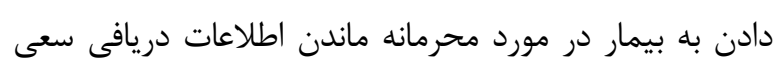

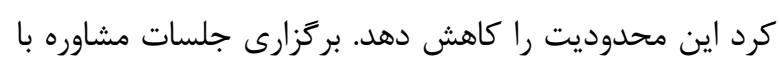

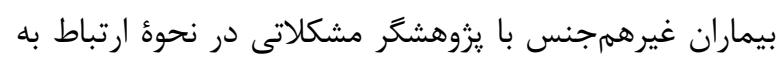

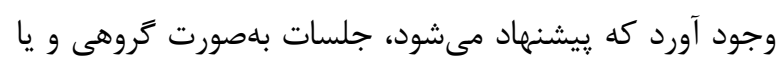

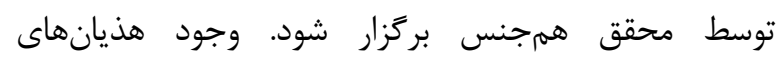

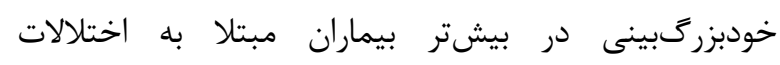

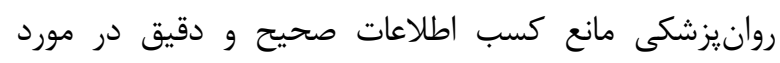

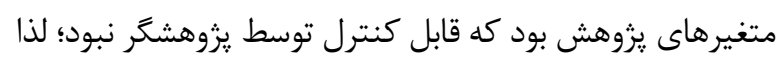

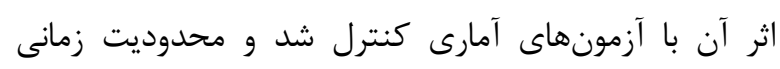

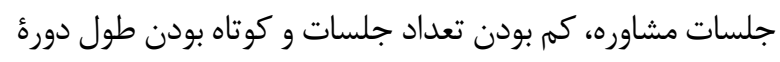

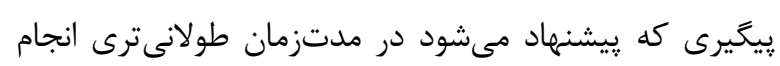

\section{نتيجه كيرى}

بلهور كلى مطالعئ فوق نشان داد كه مشاوره مىتواند،

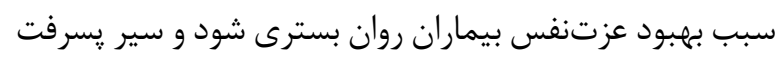

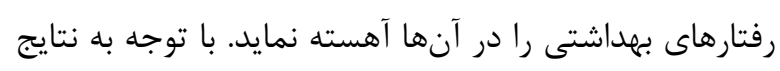

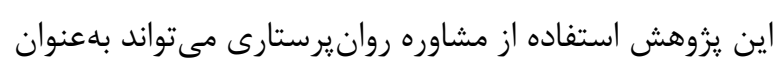

رفتارهاى ارتقاءدهنده سلامتى در مقايسه با قبل از مداخله در

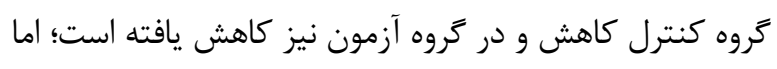

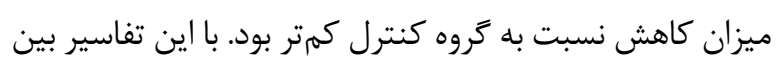

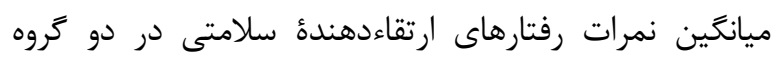

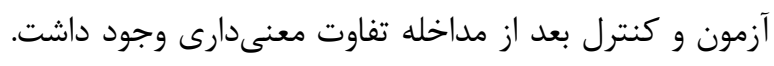

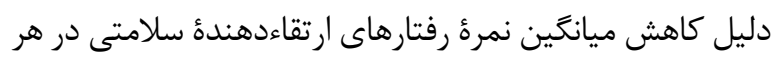

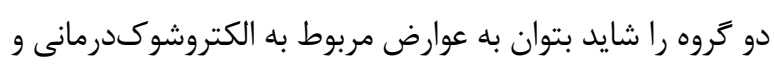
بسترى بودن بيمار و محدوديتهاى ناشى از آن آن ارتباط داد

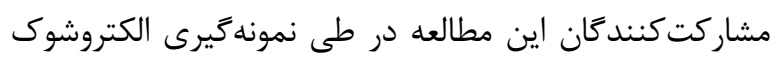

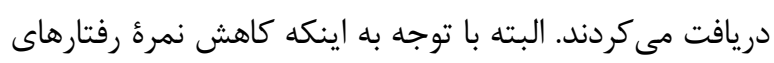

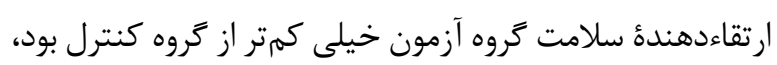

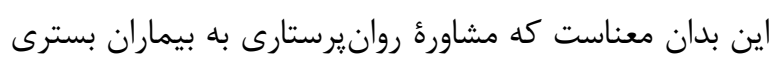

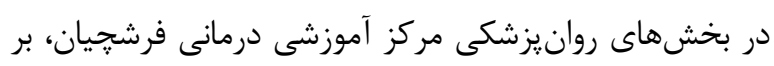

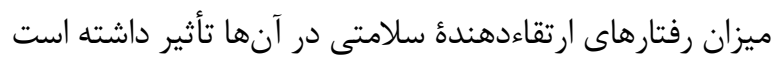

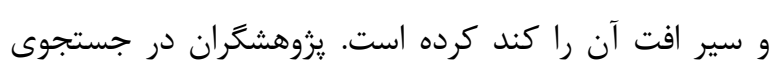

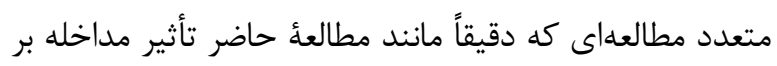

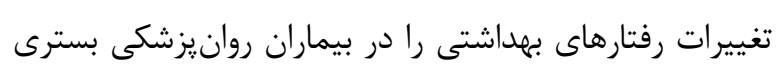

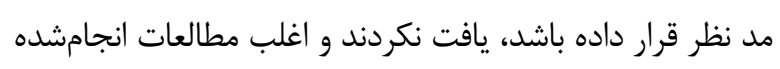

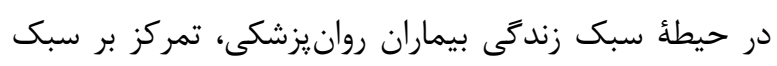

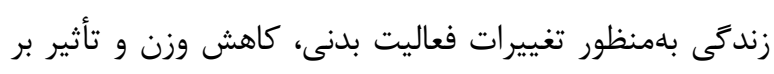

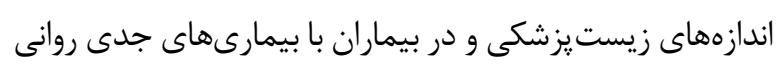

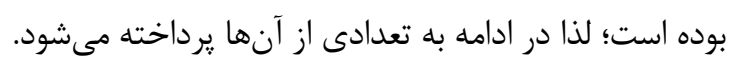
Blomqvist

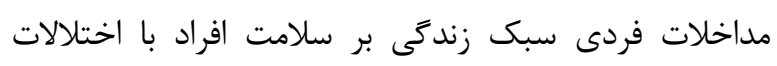

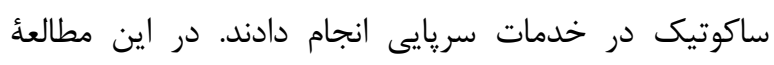

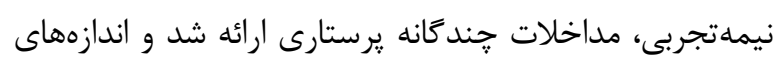

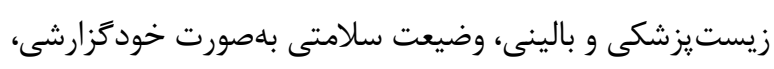

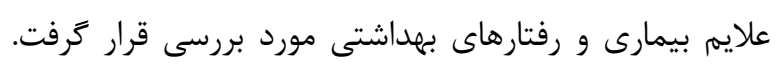

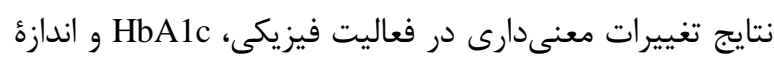

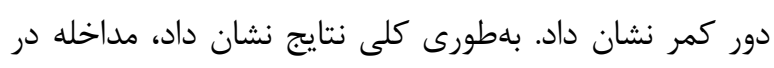

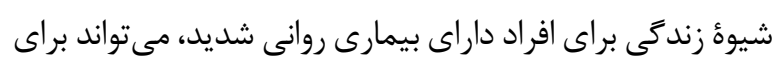

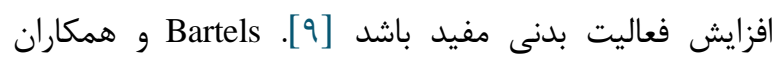

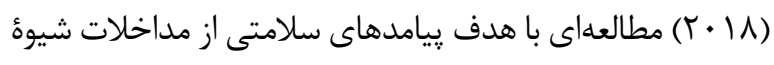

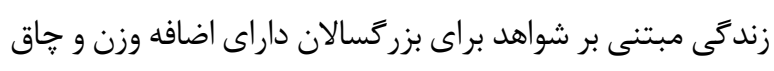

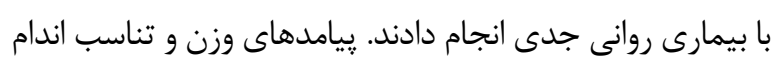

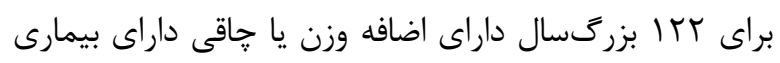

\section{Body Mass Index}




$$
\begin{aligned}
& \text { شده است . نويسندكان بر خود لازم مىدانند تا از معاونت }
\end{aligned}
$$

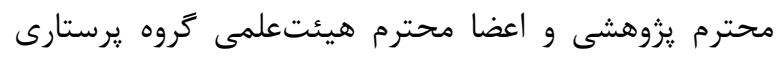

$$
\begin{aligned}
& \text { دانشگاه علوم يزشكى همدان، كاركنان محترم بيمارستان سينا }
\end{aligned}
$$

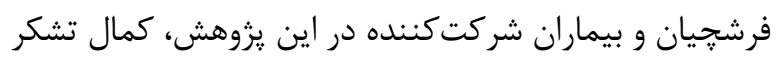

$$
\begin{aligned}
& \text { و قدردانى را نمايند. } \\
& \text { تعارض در منافع } \\
& \text { نويسند } \\
& \text { منابع مالى }
\end{aligned}
$$

\section{References}

1. Eisenberg D, Gollust SE, Golberstein E, Hefner JL. Prevalence and correlates of depression, anxiety, and suicidality among university students. Am J Orthopsychiatry. 2007;77(4):534-42. [DOI: 10.1037/0002-9432.77.4.534] [PMID]

2. Charlson F, Ommeren MV, Flaxman A, Cornett J, Whiteford H, Saxena S. New WHO prevalence estimates of mental disorders in conflict settings: a systematic review and meta-analysis. Lancet. 2019; 394: 240-48. [DOI:10.1016/S0140-6736(19)30934-1]

3. Noorbala AA, Faghihzadeh S, Kamali K, Bagheri Yazdi SA, Hajebi A, Mousavi MT, et al. Mental health survey of the Iranian adult population in 2015. Arch Iran Med. 2017;20(3):128-34.

4. Vandad Sharifi M, Hajebi A, Radgoodarzi R. Twelvemonth prevalence and correlates of psychiatric disorders in Iran: the Iranian mental health survey. Arch Iran Med. 2015;18(2):76-84.

5. Bonfioli E, Berti L, Goss C, Muraro F, Burti L. Health promotion lifestyle interventions for weight management in psychosis: a systematic review and meta-analysis of randomised controlled trials. BMC Psychiatry. 2012;12(1):78. [DOI:10.1186/1471-244X12-78] [PMID] [PMCID]

6. Chouinard V-A, Pingali SM, Chouinard G, Henderson DC, Mallya SG, Cypess AM, et al. Factors associated with overweight and obesity in schizophrenia, schizoaffective and bipolar disorders. Psychiatry Res. 2016;237:304-10.

[DOI:10.1016/i.psychres.2016.01.024] [PMID]

7. Huijg JM, Gebhardt WA, Verheijden MW, van der Zouwe N, de Vries JD, Middelkoop BJ, et al. Factors influencing primary health care professionals' physical activity promotion behaviors: a systematic review. Int J Behav Med. 2015;22(1):32-50. [DOI:10.1007/s12529014-9398-2] [PMID]

$$
\begin{aligned}
& \text { بخشى از : يروتكل درمانى بيماران روان قرارگيرد؛ و در كنار } \\
& \text { برنامه هاى دارويى در به حداقل رساندن علائم و بهبود كيفيت } \\
& \text { زندگى بيماران استفاده شود. } \\
& \text { سياسگزارى }
\end{aligned}
$$$$
\text { اين مقاله بر گرفته از طرح يزوهشى مصوبئ شوراى يزوهشى }
$$$$
\text { دانشگاه علوميزشكى و خدمات بهداشتى درمانى همدان مورخ }
$$

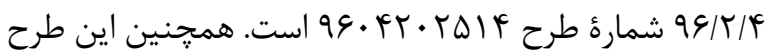

در كميته اخلاق در يروهش با كد اخلاقى IR.UMSHAREC.13960.265 و در مركز ثبت كارازمايى بالينى ايران با. شناسٔ IRCT2017061933378N3 به ثبت رسيده و تأييد

8. Saint Onge, Jarron M, Krueger, Patrick M. Health lifestyle behaviors among US adults. SSM-Population Health. 2017;3:89-98. PMID] [PMCID] [DOI:10.1016/j.ssmph.2016.12.009] [

9. Blomqvist M, Ivarsson A, Carlsson IM, Sandgren A, Jormfeldt $\mathrm{H}$. Health effects of an individualized lifestyle intervention for people with psychotic disorders in psychiatric outpatient services: a two year followup. Issues in Ment Health Nurs. 2019;40 (10):839-85. [DOI:10.1080/01612840.2019.1642425] [PMID]

10. Zeigler-Hill V. Self-Esteem (Current Issues in Social Psychology). 1st Edition ed. East Sussex: Routledge. 2017:60-91.

11. Poorgholami F, Javadpour S, Saadatmand V, Kargar Jahrom M. Effectiveness of self-care education on the enhancement of the self-esteem of patients undergoing hemodialysis. Glob J Health Sci. 2015; 8(2):132-6. [DOI:10.5539/gihs.v8n2p132] [PMID] [PMCID]

12. Marshall SL, Parker PD, Ciarrochi J, Sahdra B, Jackson CJ, Heaven PC. Self-compassion protects against the negative effects of low self-esteem: A longitudinal study in a large adolescent sample. Pers Individ Differ. 2015;74:116-21.

[DOI:10.1016/i.paid.2014.09.013]

13. Yoo T, Kim S-W, Kim S-Y, Lee J-Y, Kang H-J, Bae K$\mathrm{Y}$, et al. Relationship between suicidality and low selfesteem in patients with schizophrenia. Clin Psychopharmacol Neurosci. 2015;13(3):296-301. [DOI:10.9758/cpn.2015.13.3.296] [PMID] [PMCID]

14. Payne NA, Prudic J. Electroconvulsive therapy part II: A biopsychosocial perspective. J Psychiatr Pract. 2009; 15(5):369-390. [PMID] [PMCID] [DOI:10.1097/01.pra.0000361278.73092.85]

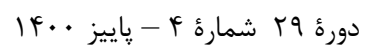

$$
\text { مجله مراقبت يُرستارى و مامايى ابنسينا }
$$


15. Sylvia I, Maria K, Bergholt D, Midtgaard J. The perspectives of former recipients and experts on stigmatization related to electroconvulsive therapy in Denmark: A focus group study. J Psychiatr Ment Health Nurs. 2018;25(5-6)358-67. [DOI:10.1111/ipm.12470] [PMID]

16. Hoffman GA, McLellan J, Hoogendoorn V, Beck AW. Electroconvulsive therapy: the impact of a brief educational intervention on public knowledge and attitudes. Int Q Community Health Educ. 2018;38(2): 129-36. [DOI:10.1177/0272684X17749939] [PMID]

17. Schoeyen HK, Kessler U, Andreassen OA, Auestad BH, Bergsholm P, Malt UF, et al. Treatment-resistant bipolar depression: a randomized controlled trial of electroconvulsive therapy versus algorithm-based pharmacological treatment. Am J Psychiatry. 2015; 172(1):41-51. [DOI:10.1176/appi.ajp.2014.13111517] [PMID]

18. Jones-Smith E. Theories of Counseling and Psychotherapy: An Integrative Approach. 2nd Edition ed: SAGE Publications;2014.

19. Borzu R, Safari M, Khodavisi M, Torkaman B. The viewpoints of nurses towards applicability of nursing curriculum in hospitals affiliated to Hamedan university of medical sciences. Iran J Med Educ. 2008;8(2):205-11.

20. Shafiabadi A, Naseri GhR. Theories of counseling and psychotherapy. Tehran: Center for Academic Publication; 2019:324.

21. Chien W-T, Leung S-F, Chu CS. A nurse-led, needsbased psycho-education intervention for Chinese patients with first-onset mental illness. Contemp Nurse. 2012;40(2):194-209. [DOI:10.5172/conu.2012.40.2.194] [PMID]

22. Farzadmehr M, Fallahi Khoshknab M, Hosseini MA, Khankeh HR. The effect of nursing consultation on anxiety and satisfaction of patient's families at the cardiac surgical intensive care unit. Iran J Psy Nurs. 2016;4(2):57-64. [DOI:10.21859/ijpn-04027]

23. Ebrahimi H, Navidian A, Keykha R. Effect of supportive nursing care on self esteem of patients receiving electroconvulsive therapy: A randomized controlled clinical trial. J Caring Sci. 2014;3(2):149-56.

24. Sharifi Neyestanak ND, Ghodoosi Boroojeni M, Seyedfatemi N, Heydari M, Hoseini AF. Self esteem and its associated factors in patients with multiple sclerosis. Iran J Nurs. 2012;25(78):14-22.

25. Rajabi Gh, Karjo K. A study of confirmatory structure two-factor model of the Persian version Rosenberg self- esteem scale. J Psychol Models Methods. 2012;2(6):3343.

26. Walker SN, Sechrist KR, Pender NJ. The healthpromoting lifestyle profile: development and psychometric characteristics. Nurs Res. 1987;36(2): 7681. [DOI:10.1097/00006199-198703000-00002] [PMID]

27. Walker SN, Sechrist KR, Pender NJ. Health promotion model-instruments to measure health promoting lifestyle: Health-promoting lifestyle profile [HPLP II](Adult version). 1995.

28. Mohammadi Zeidi I, Pakpour Hajiagha A, Mohammadi Zeidi B. Reliability and validity of persian version of the health-promoting lifestyle profile. J Maz Univ Med Sci. 2012;21(1):102-13

29. Sadeghian E, Rostami P, Shamsaei F, Tapak L. The effect of counseling on stigma in psychiatric patients receiving electroconvulsive therapy: A clinical trial study. Neuropsychiatr Dis Treat. 2019;15:3419-27. [DOI:10.2147/NDT.S233094] [PMID] [PMCID]

30. Carson VB, Arnold N. Mental health nursing: The nurse-patient journey: WB Saunders Tokyo; 2000.

31. Kim N-R, Jang MH. Effects of self-assertive training applying reality therapy techniques on self-esteem and internalized stigma in schizophrenia patients. J Korean Acad Psychiatr Ment Health Nursing. 2019;28(1):3749. [DOI:10.12934/ikpmhn.2019.28.1.37]

32. Savaşan A, Çam O. The effect of the psychiatric nursing approach based on the tidal model on coping and self-esteem in people with alcohol dependency: a randomized trial. Arch Psychiatr Nurs. 2017;31(3): 274-81. [DOI:10.1016/j.apnu.2017.01.002] [PMID]

33. Mejías JA, Jurado MM, Tafoya SA, Romo F, Sandoval JR, Beltrán-Hernández L. Effects of group psychotherapy on depressive and anxious symptoms, self-esteem and social adaptation in college students. Couns Psychother Res. 2019;20(1):46-56. [DOI:10.1002/capr.12254

34. Bartels SJ, Aschbrenner KA, Pratt SI, Naslund JA, Scherer EA, Zubkoff $\mathrm{L}$, et al. Implementation of a lifestyle intervention for people with serious mental illness in state-funded mental health centers. Psychiatr Serv. 2018;69(6):664-70. [DOI:10.1176/appi.ps.201700368] [PMID]

35. Naslund JA, Aschbrenner KA, Scherer EA, Pratt SI, Wolfe RS, Bartels SJ. Lifestyle intervention for people with severe obesity and serious mental illness. Am J Prev Med. 2016;50(2):145-53. [PMID] [PMCID] [DOI:10.1016/j.amepre.2015.07.012]

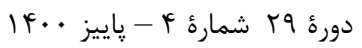

